\title{
LESSON 45
} lation

\section{Tabulation}

Clear margins and tabs.
Vertical Display of Ruled Tabu-

The following display is to be typed on a sheet of A5 paper $(210 \times 148 \mathrm{~mm})$ with equal margins at the top and bottom of the sheet.

\section{English Towns}

\begin{tabular}{|l|l|l|}
\hline Abberley & Bainbridge & Cabus \\
Abingdon & Bakewell & Cadnam \\
Abridge & Balcome & Cambridge \\
Accrington & Banbury & Caton \\
\hline
\end{tabular}

Either

Step 1 Set the tabs in the usual way.

Step 2 Find the middle of the length of the paper by measuring it or by lightly folding it into two and mark the mid-point. Put the paper into the machine against the paper guide at 0 on the scale and find the mid-point marked.

Step 3 Turn the roller towards you (anti-clockwise) one 'click' or half space for each line and space down the display. Leave 2 spaces after the title. You will turn: English Towns, blank line, blank line, ruled line, space after the ruled line, Abberley, Abingdon, Abridge Accrington and the bottom ruled line.

(If your machine does not have a half-line spacer, turn the roller one 'click' for every 2 lines and spaces.) Type the display.

Step 1 Set the tabs in the usual way. Count the number of lines and spaces down the display and take it from the number of lines down a sheet of A5 paper $(210 \times 148 \mathrm{~mm})$. There are 35 lines down the sheet and 10 lines in the display:

1. English Towns 2. Space 3. Space 4. Ruled line 5. Blank line after the ruled line 6. Abberley 7. Abingdon 8. Abridge 9. Accrington 10. Bottom ruled line.

Available down the sheet, 35. Used, 10. $35-10=25$.

Step 2 Divide the number of spaces left by 2 to give equal margins top and bottom.

Margins $=$ Left $\div 2 . \quad 25 \div 2=12 \frac{1}{2}$

Leave the odd number of lines at the bottom of the sheet - leave 12 at the top and 13 at the bottom.

Step 3 Put the paper into the machine against the paper guide at 0 on the scale on the left and turn up 13 single lines to leave the required 12 at the top.

Type the display.

Tabulation 14

PAPER: A5 $(210 \times 148 \mathrm{~mm})$.

Equal margins at top and bottom.

TARGET TIME: 15 minutes.

UNIT 12

LESSON 45 